\title{
OSL Chronology of the Siling Co Paleolithic Site in Central Tibetan Plateau
}

\author{
Lan Luo ${ }^{1,2}$, Zhongping Lai ${ }^{1,3 *}$, Wenhao Zheng ${ }^{4}$, Yantian $X u^{1 *}$, Lupeng $Y u^{5}$, Chang Huang ${ }^{1,6}$ \\ and Hua $\mathrm{Tu}^{1}$ \\ ${ }^{1}$ Institute of Marine Sciences, Guangdong Provincial Key Laboratory of Marine Biotechnology, Shantou University, Shantou, \\ China, ${ }^{2}$ Department of Physics, Purdue Rare Isotope Measurement Laboratory, Purdue University, West Lafayette, IN, \\ United States, ${ }^{3}$ Southern Marine Science and Engineering Guangdong Laboratory (Zhuhai), Zhuhai, China, ${ }^{4}$ Zhejiang Institute of \\ Geology and Mineral Resources, Hangzhou, China, ${ }^{5}$ Shandong Provincial Key Laboratory of Water and Soil Conservation and \\ Environmental Protection, School of Resource and Environmental Sciences, Linyi University, Linyi, China, ${ }^{6}$ Department of Earth \\ Sciences, The University of Hong Kong, Hong Kong, SAR China
}

\section{OPEN ACCESS}

Edited by:

Shiyong Yu,

Jiangsu Normal University, China

Reviewed by:

Shugang Kang,

Institute of Earth Environment (CAS),

China

Weiming Liu,

Chinese Academy of Sciences (CAS),

China

Luke Gliganic,

University of Wollongong, Australia

*Correspondence:

Zhongping Lai

zhongping.lai@yahoo.com Yantian Xu

xuyantian@hotmail.com

Specialty section:

This article was submitted to Quaternary Science, Geomorphology and Paleoenvironment,

a section of the journal

Frontiers in Earth Science

Received: 24 April 2021

Accepted: 08 July 2021

Published: 20 September 2021

Citation:

Luo L, Lai Z, Zheng $W, X u Y, Y u L$, Huang $C$ and Tu H (2021) OSL Chronology of the Siling Co Paleolithic Site in Central Tibetan Plateau.

Front. Earth Sci. 9:699693. doi: 10.3389/feart.2021.699693
When and how was the Tibetan Plateau (TP), one of the least habitable regions on Earth, occupied by humans are important questions in the research of human evolution. Among tens of Paleolithic archaeological sites discovered over the past decades, only five are considered coeval with or older than the Last Glacial Maximum (LGM, 27-19 ka). As one of them, the Siling Co site in the central TP was previously announced to be $\sim 40-30 \mathrm{ka}$ based on radiocarbon dating and stratigraphic correlation. Given the loose chronological constraint in previous studies, we here re-examined the chronology of the Siling Co site with the optically stimulated luminescence (OSL) dating technique. Four sections from the paleo-shoreline at an elevation of $\sim 4,600 \mathrm{~m}$ in southeastern Siling Co were investigated, with stone artifacts found from the ground surface. Dating results of nine samples delineated the age of $\sim 4,600 \mathrm{~m}$ paleo-shoreline to be $\sim 10-7 \mathrm{ka}(\sim 8.54 \pm 0.21 \mathrm{ka}$ in average). This age indicates that the Siling Co site is not earlier than the early Holocene, much younger than the former age. The revised age of the Siling Co site is consistent with the wet and humid climate conditions on the TP during the early Holocene.

Keywords: OSL, Siling Co, paleolithic site, Tibetan Plateau, paleo-shoreline

\section{INTRODUCTION}

With an average elevation of $\sim 4,000 \mathrm{~m}$, a mean annual temperature close to the freezing point of water, and only half the concentration of oxygen at the sea level, the Tibetan Plateau (TP) offers one of the most demanding and hostile living conditions to humans. For this reason, the timing and mechanism of human colonization of this region as well as the accompanying cultural and physiological responses to numerous environmental extremes are of high concern and heatedly debated (Zhang and Li, 2002; Madsen et al., 2006; Zhao et al., 2009; Brantingham et al., 2010; Simonson et al., 2010; Yi et al., 2010; Chen et al., 2015; Meyer et al., 2017; Zhang et al., 2018; Chen et al., 2019; Zhang et al., 2020).

Over the past six decades, at least 38 Paleolithic archaeological sites with ages earlier than the middle Holocene have been discovered on the TP, and five of them were even considered coeval with or prior to the Last Glacial Maximum (LGM) (Figure 1A): Baishiya Karst Cave ( 190-17 ka) (Zhang et al., 2020), Nwya Devu (ND) ( 40-30 ka) (Zhang et al., 2018), Siling Co ( 40-30 ka) (Yuan et al., 2007), Xiao Qaidam ( 30 ka) (Huang et al., 1987), and Chusang (or Quesang, $20 \mathrm{ka}$ ) (Zhang and Li, 

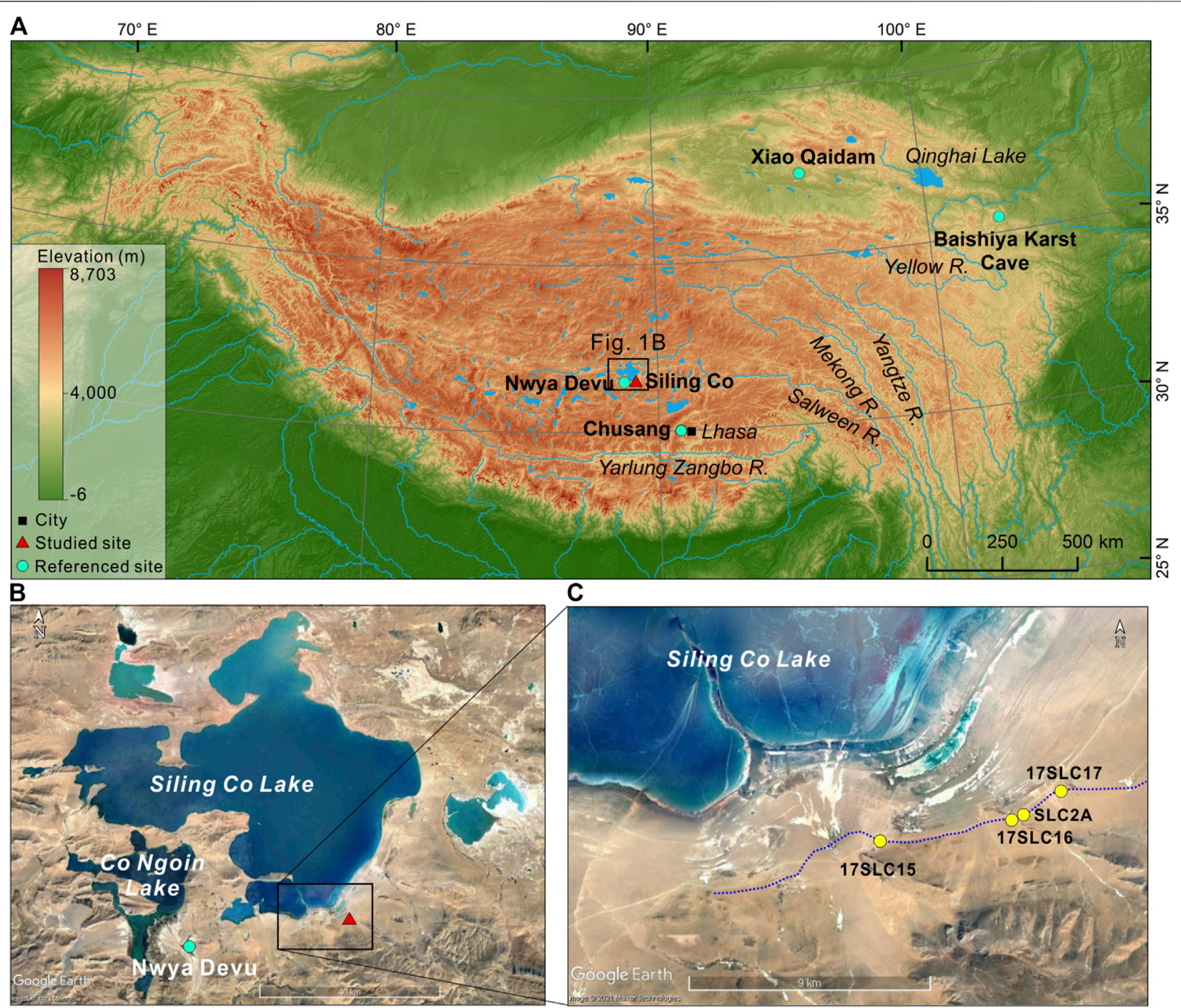

FIGURE 1 | The locations of the studied Siling Co Paleolithic site and sections. (A) Map showing the locations of the Siling Co site and four other Paleolithic sites (light blue dots) on the Tibetan Plateau with possible ages of the LGM or older. (B) Location of the Siling Co site in relation to Siling Co Lake, Co Ngoin Lake, and the Nwya Devu site. (C) Locations of the four investigated sections (yellow dots) along the paleo-shoreline at an elevation of $\sim 4,600 \mathrm{~m}$ (blue dashed line). Artifacts were found on the ground surface of sections 17SLC16 and SLC2A. Digital elevation model data for (A) from http://vterrain.org/Elevation/global.html. Satellite imagery for (B,C) courtesy of Google Earth.

2002). However, recent re-examinations raised the possibility of age overestimation in some of these earliest sites. Based on 10 samples dated with the optically stimulated luminescence (OSL) method, Sun et al. (2010) deduced that the age of the Xiao Qaidam site was most likely between $\sim 3$ and $11 \mathrm{ka}$, much younger than the previously proposed $\sim 30 \mathrm{ka}$ according to radiocarbon dating, stratigraphic correlation, and speculation. Likewise, the age of the Chusang site, which consists of 19 human hand- and footprints found on the surface of fossil travertine, was revised from a previous OSL-derived timing of LGM (Zhang and $\mathrm{Li}, 2002$ ) to no earlier than $\sim 12.67$ and 8.20 thousand calibrated years before present (ka cal. BP) by combined ${ }^{14} \mathrm{C},{ }^{230} \mathrm{Th} / \mathrm{U}$, and OSL dating (Meyer et al., 2017). Age overestimation of vital Paleolithic sites would cause serious misunderstanding of the pattern and driving mechanism of settlement on the TP. Therefore, chronological revisiting of more archaeological sites is necessary.

In this article, we focus on the Siling Co ("Co" means "lake" in Tibetan) site whose age was only loosely constrained by stratigraphic correlation with ${ }^{14} \mathrm{C}$-dated lacustrine terraces (paleo-shorelines) (Yuan et al., 2007). Although some dating results obtained with OSL and cosmogenic nuclide techniques have been reported (Li et al., 2009; Kong et al., 2011; Shi et al., 2015, 2017), their stratigraphic relationship with stone artifactbearing layers were vaguely described due to research emphasis on paleoclimate and/or tectonics. Thus, we re-investigated the chronology of the Siling Co site with the OSL method, which is suitable for coarse-grained, carbon-deficient shoreline deposits. 


\section{STUDY AREA AND SAMPLE COLLECTION}

\section{Regional Setting of Siling Co}

Siling Co $\left(88^{\circ} 31^{\prime}-89^{\circ} 22^{\prime} \mathrm{E}, 31^{\circ} 30^{\prime}-32^{\circ} 20^{\prime} \mathrm{N}\right)$ is a closed lake in the interior of the TP and is fed by precipitation and melting glaciers from a drainage area of $57,200 \mathrm{~km}^{2}$. With a continued rise in the water level during the past few decades, it has become the largest endorheic lake in the central TP with a water area of $2,323.6 \mathrm{~km}^{2}$ (Meng et al., 2012). Quaternary fluctuations of the lake level have left multiple paleo-shorelines, mainly composed of mixed gravel and sand, with the highest one lying at an elevation of $\sim 4,600 \mathrm{~m}$ above the sea level (masl), nearly $50 \mathrm{~m}$ above the current lake level at $\sim 4,550 \mathrm{~m}$ (Shi et al., 2015).

During a joint Sino-Japan expedition in 1988, some stone artifacts were found from the $4,600 \mathrm{~m}$ paleo-shoreline in situ and the surface of a natural alluvial cone near a rock hill $\left(31^{\circ} 31^{\prime} \mathrm{N}, 89^{\circ} 14^{\prime} \mathrm{E}\right)$ in southeastern Siling Co (Yuan et al., 2007), about $39 \mathrm{~km}$ to the east of the latest reported Nywa Devu site situated on a terrace of Co Ngoin Lake (Figure 1B). As direct ${ }^{14} \mathrm{C}$ dating of carbonates failed due to severe contamination from "dead carbon," the stone artifact-yielding paleo-shoreline was assigned an age of $\sim 40-30$ ka based on stratigraphic correlation with nearby ${ }^{14} \mathrm{C}$-dated paleo-shorelines (Yuan et al., 2007).

\section{OSL Sample Collection}

In our 2015-2017 fieldwork, an assemblage of 36 stone artifacts, including 15 flakes, 17 tools, and four micro-cores, were spotted on the surface of the $\sim 4,600 \mathrm{~m}$ paleo-shoreline in southeastern Siling Co (Figure 2). The artifacts are mostly made of dark grey slate, and the raw materials could be readily found in surrounding areas. Surfaces and edges of the artifacts show little signs of erosion or rounding, suggesting that they were not transported from elsewhere. The allogenic possibility is further ruled out by the absence of higher paleo-shorelines around the site. Given similarities in geographic locations and lithic characteristics, we assume that this site is quite close to the one described in Yuan et al. (2007).

In the field, shoreline sediments can be distinguished by features such as bedding (e.g., foreset bedding), color, sorting, and rounding. At Siling Co, the shorelines are typically associated with sandy or gravelly deposits with cross-bedded layers. Four freshly cleaned sections from the $\sim 4,600 \mathrm{~m}$ paleo-shoreline were chosen for a chronological study (Figures 1C, 3), including three hand-excavated pits (17SLC16, 17SLC17, and SLC2A) and a section exposed by road construction (17SCL15). Among them, sections 17SLC16 and SLC2A are where the stone artifacts were discovered on the surface (Figure 3). Lithological details of these four sections are presented in Table 1. A total of nine OSL samples were collected, with one from 17SLC16, one from 17SLC17, two from SLC2A (duplicate samples), and five from 17SLC15 (Figure 3).

During the sample collection, stainless tubes $(20-25 \mathrm{~cm}$ in length and $5 \mathrm{~cm}$ in diameter) were hammered into freshly cleaned vertical sections and then wrapped with black plastic bags and taped to avoid light exposure and moisture loss. For sediments rich in coarse-grained sand and gravel, two or three adjacent tubes were obtained for each sample to ensure enough materials

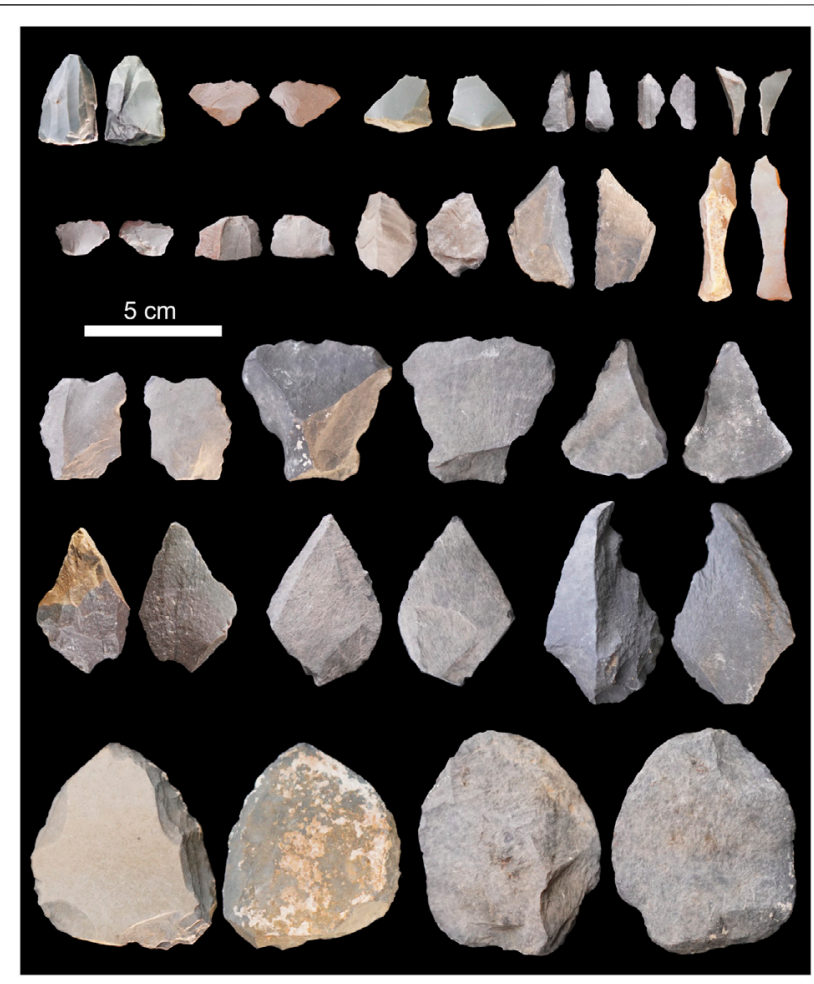

FIGURE 2 | Stone artifacts found in the Siling Co site. Artifacts were collected from the ground surface of sections 17SLC16 and SLC2A in this study.

for the following experiment. Additional sediments for dose rate determination were taken from the same positions of each sample.

\section{OSL DATING}

\section{Sample Pretreatment}

Sample preparation was conducted under subdued red light according to routine procedures. Coarse-grained quartz was used for equivalent dose $\left(D_{e}\right)$ determination. First, $2-3 \mathrm{~cm}$ thick sediments at both ends of the tube were discarded because of potential light exposure. The remaining part was wet sieved to remove $>300 \mu \mathrm{m}$ gravels, followed by treatment with $10 \%$ hydrochloric acid $(\mathrm{HCl})$ and $30 \%$ hydrogen peroxide $\left(\mathrm{H}_{2} \mathrm{O}_{2}\right)$ to eliminate carbonates and organic matter, respectively. Then, the coarse-grained component $(90-125,90-150$, or $150-200 \mu \mathrm{m}$, depending on availability) was separated by wet sieving and treated with heavy liquid (aqueous sodium polytungstate, SPT) of 2.62 and $2.70 \mathrm{~g} / \mathrm{cm}^{3}$ to further isolate the quartz-rich fraction. Finally, this fraction was etched with $40 \%$ hydrofluoric acid (HF) for $40 \mathrm{~min}$ to corrode residual feldspars and the outer alpha-irradiated rind of quartz grains, followed by a $10 \% \mathrm{HCl}$ rinse to eliminate fluoride precipitates. The purity of the isolated quartz fraction was checked by infrared light stimulation (IRSL), and repeated treatment with HF would be carried out if obvious IRSL signals were observed until passing 
A
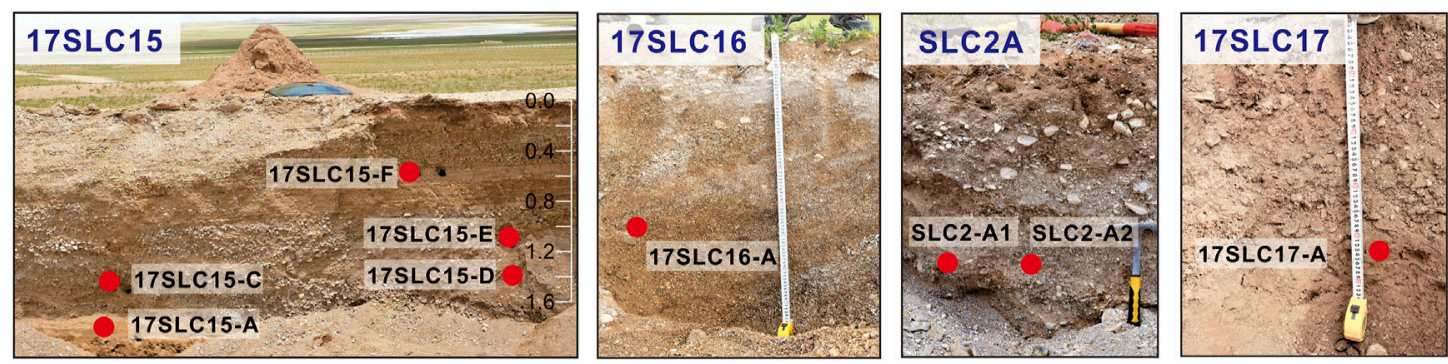

B
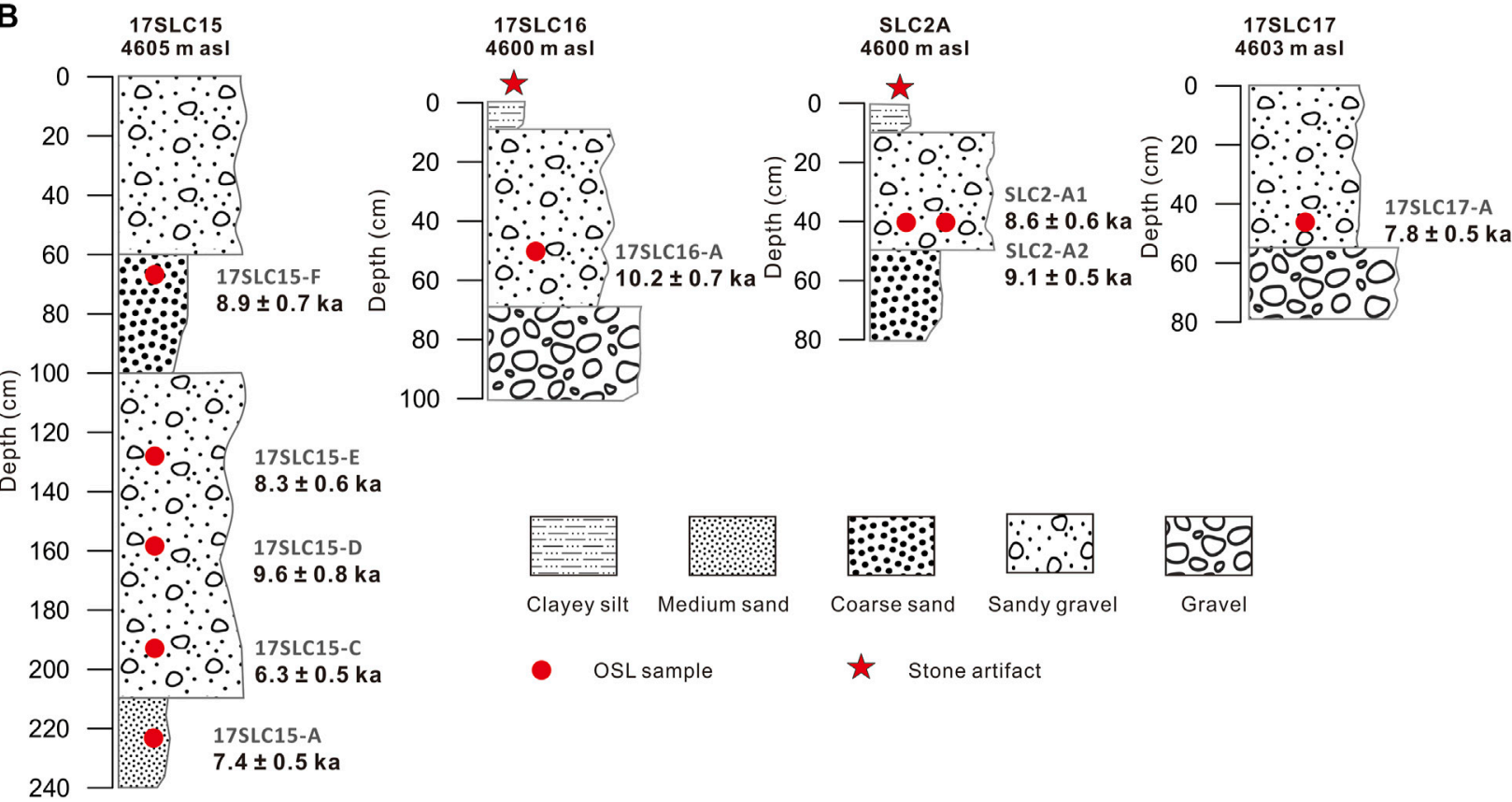

(1)

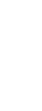

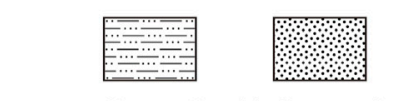

Clayeysilt Medium sand

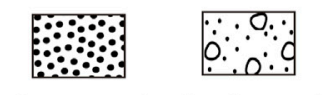

Coarse sand Sandy gravel

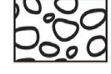

Gravel

- OSL sample

$\star \quad$ Stone artifact

FIGURE 3 | (A) Photos showing the four studied sections and sampling positions. (B) Lithological logs of sections and OSL ages.

the test. After re-sieving with 90- or $150-\mu \mathrm{m}$ sieves, the separated quartz grains were mounted as monolayers onto the central part $(2-3 \mathrm{~mm}$ in diameter) of $9.7 \mathrm{~mm}$-diameter steel discs with silicone oil adhesive.

\section{OSL Measurement}

Luminescence was measured by a Risø Model DA-20 TL/OSL reader equipped with blue LEDs $(470 \pm 20 \mathrm{~nm})$, infrared LEDs $(875 \pm 80 \mathrm{~nm})$, and $\mathrm{a}^{90} \mathrm{Sr} /{ }^{90} \mathrm{Y}$ beta source. The quartz OSL signals were stimulated by blue LEDs (90\% diode power) for $40 \mathrm{~s}$ at $130^{\circ} \mathrm{C}$ and detected by a 9235QA photomultiplier tube after filtering through a $7.5 \mathrm{~mm}$ Hoya U-340 filter. The OSL signals of the first 0.64 -s integral subtracted by the background (last $10 \mathrm{~s}$ ) were used for growth curve construction.

The single aliquot regenerative dose (SAR) (Murray and Wintle, 2000) protocol combined with the standardized growth curve (SGC) method (Roberts and Duller, 2004; Lai, 2006; Lai et al., 2007) was employed for $D_{\mathrm{e}}$ determination. Prior to the routine experiment, preheat plateau and dose recovery tests were carried out on a representative sample SLC2A-1 to choose an appropriate preheat temperature and to assess the overall performance of the SAR protocol, respectively (Murray and Wintle, 2003). In the preheat plateau test, preheat temperatures varied from $220^{\circ} \mathrm{C}$ to $300^{\circ} \mathrm{C}$ at $20^{\circ} \mathrm{C}$ increments, while the cut-heat was fixed at $220^{\circ} \mathrm{C}$ for all the measurements; for each preheat temperature step, the mean $D_{\mathrm{e}}$ of four aliquots was calculated. $260^{\circ} \mathrm{C}$ was selected as an appropriate preheat temperature as was within the plateau region (Figure 4A). In the dose recovery test, four aliquots were bleached by blue light for $100 \mathrm{~s}$ before receiving a laboratory dose, and the SAR protocol was then used to recover this known dose. The resultant ratios of measured to given doses were within $10 \%$ uncertainty of unity, validating the overall protocol conditions in this study (Figure 4B).

In the SAR-SGC protocol for $D_{\mathrm{e}}$ determination, six or more aliquots were first measured by the SAR protocol and yielded $6 D_{\mathrm{e}} \mathrm{s}$ and 6 growth curves, which were fitted by linear or single exponential functions. These $D_{\mathrm{e}} \mathrm{s}$ and growth curves were accepted only when 1) the recycling ratio fell into the acceptance range of $0.9-1.1$ and 2) the recuperation, calculated by comparing the sensitivity-corrected OSL signal of $0 \mathrm{~Gy}\left(L_{0} / T_{0}\right)$ with the sensitivity-corrected natural OSL signal $\left(L_{n} / T_{n}\right)$, was 
TABLE 1 | Lithological details of studied sections from the paleo-shoreline at $~ 4,600$ masl.

\begin{tabular}{|c|c|c|}
\hline Section ID & Depth (cm) & Description \\
\hline \multirow[t]{4}{*}{ 17SLC15 $\left(31^{\circ} 30.6^{\prime} \mathrm{N}, 89^{\circ} 09.0^{\prime} \mathrm{E}\right.$, ground altitude: 4,605 m) } & $0-60$ & Grayish-brown sandy gravel with low-angle cross-beddings \\
\hline & $60-100$ & Brownish-gray coarse sand \\
\hline & $100-210$ & Brownish-gray sandy gravel with cross-beddings \\
\hline & $210-240$ & Brownish-yellow medium sand \\
\hline \multirow[t]{3}{*}{17 SLC16 $\left(31^{\circ} 31.2^{\prime} \mathrm{N}, 89^{\circ} 12.0^{\prime} \mathrm{E}\right.$, ground altitude: 4,600 m) } & $0-10$ & Brownish-yellow clayey silt \\
\hline & $10-70$ & Grayish-yellow sandy gravel with low-angle cross-beddings \\
\hline & $70-100$ & Pale gray gravel with low angle cross-beddings, calcareously cemented in the surface \\
\hline \multirow[t]{2}{*}{ 17SLC17 (3131.8'N, 89¹3.2'E, ground altitude: 4,603 m) } & $0-55$ & Yellowish-brown sandy gravel with horizontal beddings \\
\hline & $>55$ & Yellowish-brown gravel \\
\hline \multirow[t]{3}{*}{ SLC2A $\left(31^{\circ} 31.3^{\prime} \mathrm{N}, 89^{\circ} 12.5^{\prime} \mathrm{E}\right.$, ground altitude: $\left.4,600 \mathrm{~m}\right)$} & $0-10$ & Reddish-brown clayey silt \\
\hline & $10-50$ & Grayish-yellow sandy gravel with $\sim 10^{\circ}$ cross-beddings \\
\hline & $>50$ & Brownish-gray coarse sand \\
\hline
\end{tabular}
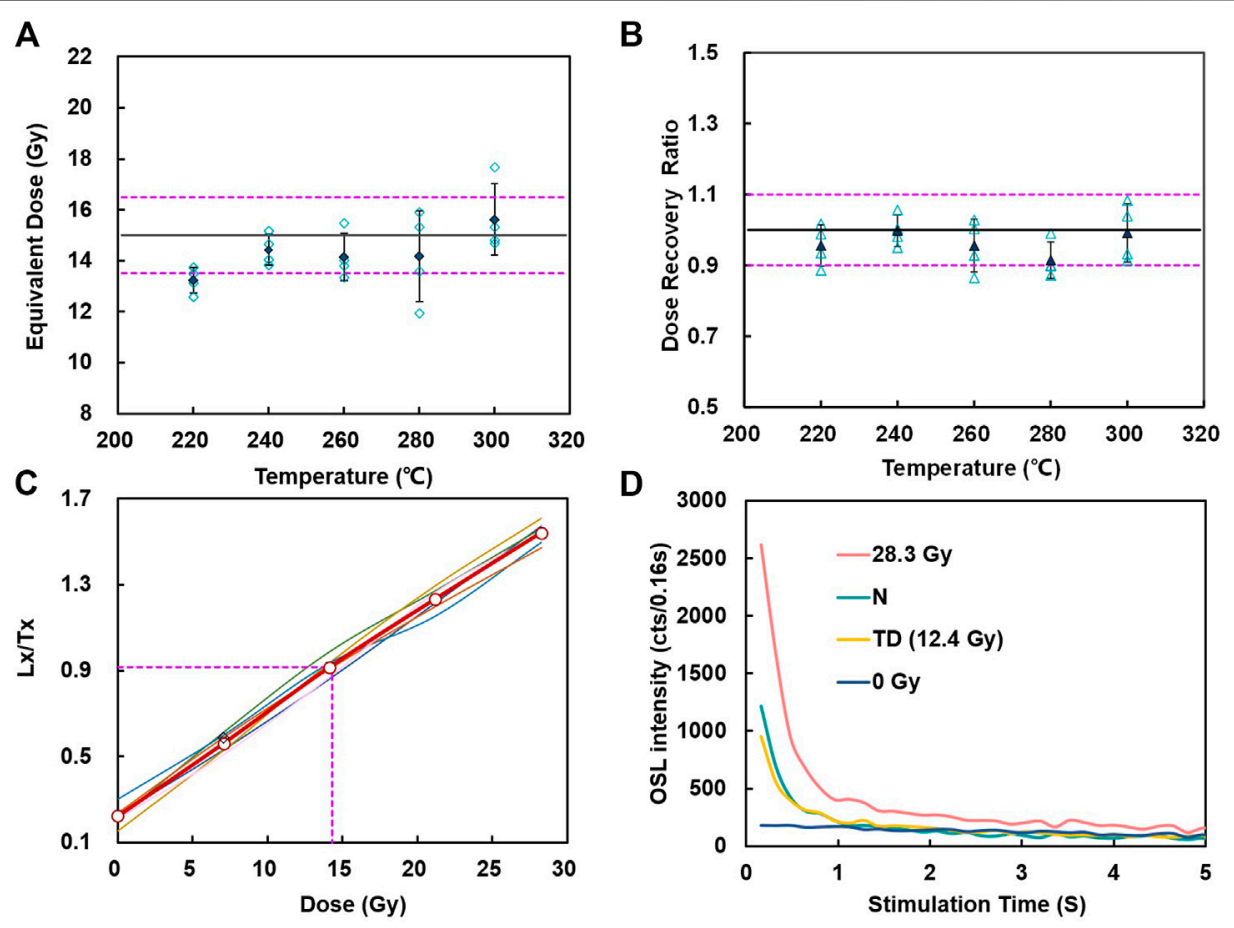

FIGURE 4 | Luminescence characteristics of sample SLC2A-1. (A) Preheat plateau test and (B) dose recovery test. (C) Growth curves of six aliquots and the standardized growth curve (SGC, the red line, and empty circles) averaged from them. Dashed lines indicate the projection of a sensitivity-corrected natural OSL signal onto the SGC to yield a $D_{\mathrm{e}}$ value. (D) Decay curves, where $\mathrm{N}$ is the natural dose and TD is the test dose.

$<5 \%$. The accepted growth curves were then averaged to give an SGC for the sample. Afterwards, the $L_{\mathrm{n}} / T_{\mathrm{n}}$ of at least 12 more aliquots of this sample were measured under the same experimental conditions and projected onto the SGC to yield $D_{\mathrm{e}} \mathrm{s}$. The difference in $\mathrm{D}_{\mathrm{e}}$ errors determined by the SAR and SGC methods are minor and negligible. So, the SAR $D_{\mathrm{e}} \mathrm{s}$ and SGC $D_{\mathrm{e}} \mathrm{s}$ were treated equally in the following analysis after removing a few obvious outliers (at most 3) (Table 2).

The shoreline sediments are usually transported, washed, and sorted before deposition and thus should be well bleached. The overdispersion (OD) values of most samples were relatively low (20\%) (Table 2 and Supplementary Figure S1), suggesting that $D_{\mathrm{e}} \mathrm{s}$ of all aliquots were centering on some average value. Therefore, the central age model (CAM) was used to calculate the final $D_{\mathrm{e}}$.

\section{Dose Rate Measurement}

The concentrations of uranium (U), thorium (Th), and potassium (K) of dose-rate samples were determined through either neutron activation analysis (NAA) or ICP-MS (for U and Th) and ICP-AES (for K). A water content value of $5 \%$ was assigned to all paleo-shoreline sediments 
TABLE 2 | OSL dating results.

\begin{tabular}{|c|c|c|c|c|c|c|c|c|c|c|c|}
\hline \multirow[t]{2}{*}{ Sample ID } & \multirow{2}{*}{$\begin{array}{c}\text { Depth } \\
\text { (m) }\end{array}$} & \multirow{2}{*}{$\begin{array}{c}\text { Grain } \\
\text { size }(\mu \mathrm{m})\end{array}$} & \multicolumn{2}{|c|}{ Aliquot No. } & \multirow[t]{2}{*}{ K (\%) } & \multirow[t]{2}{*}{ Th (ppm) } & \multirow[t]{2}{*}{ U (ppm) } & \multirow{2}{*}{$\begin{array}{c}\text { Dose rate } \\
\text { (Gy/ka) }\end{array}$} & \multirow[t]{2}{*}{$D_{\mathrm{e}}$ (Gy) } & \multirow{2}{*}{$\begin{array}{c}\text { Over- } \\
\text { dispersion } \\
(\%)\end{array}$} & \multirow[t]{2}{*}{ Age (ka) } \\
\hline & & & Accepted $^{\mathrm{a}}$ & Rejected $^{\mathbf{b}}$ & & & & & & & \\
\hline 17SLC15-F & 0.65 & $90-150$ & $19(6)$ & 2 & $1.01 \pm 0.04$ & $5.73 \pm 0.20$ & $2.17 \pm 0.09$ & $2.22 \pm 0.11$ & $19.77 \pm 1.28$ & $23.0 \pm 3.9$ & $8.9 \pm 0.7$ \\
\hline 17SLC15-E & 1.30 & $90-150$ & $19(6)$ & 2 & $0.75 \pm 0.04$ & $5.74 \pm 0.20$ & $3.43 \pm 0.13$ & $2.22 \pm 0.10$ & $18.52 \pm 0.96$ & $17.5 \pm 3.0$ & $8.3 \pm 0.6$ \\
\hline 17SLC15-D & 1.60 & $90-125$ & $20(7)$ & 2 & $0.63 \pm 0.03$ & $5.02 \pm 0.18$ & $2.67 \pm 0.10$ & $1.88 \pm 0.08$ & $18.00 \pm 1.18$ & $26.1 \pm 4.4$ & $9.6 \pm 0.8$ \\
\hline 17SLC15-C & 1.95 & $90-125$ & $19(6)$ & 2 & $1.36 \pm 0.05$ & $7.90 \pm 0.25$ & $2.39 \pm 0.10$ & $2.67 \pm 0.13$ & $16.69 \pm 0.88$ & $15.3 \pm 2.8$ & $6.3 \pm 0.5$ \\
\hline 17SLC15-A & 2.25 & $90-125$ & $19(6)$ & 1 & $1.85 \pm 0.06$ & $10.90 \pm 0.32$ & $2.14 \pm 0.09$ & $3.25 \pm 0.16$ & $23.95 \pm 1.29$ & $19.5 \pm 3.4$ & $7.4 \pm 0.5$ \\
\hline 17SLC16-A & 0.50 & $90-150$ & $19(6)$ & 1 & $0.59 \pm 0.03$ & $4.60 \pm 0.16$ & $2.23 \pm 0.09$ & $1.77 \pm 0.09$ & $18.50 \pm 1.08$ & $22.0 \pm 3.8$ & $10.2 \pm 0.7$ \\
\hline 17SLC17-A & 0.50 & $90-125$ & $19(6)$ & 2 & $1.67 \pm 0.06$ & $10.80 \pm 0.31$ & $2.28 \pm 0.09$ & $3.22 \pm 0.16$ & $25.59 \pm 1.44$ & $19.3 \pm 3.4$ & $7.8 \pm 0.5$ \\
\hline SLC2-A1 & 0.40 & $90-150$ & $19(7)$ & 2 & $0.57 \pm 0.03$ & $4.17 \pm 0.15$ & $2.29 \pm 0.09$ & $1.74 \pm 0.08$ & $15.01 \pm 0.63$ & $14.5 \pm 2.6$ & $8.6 \pm 0.6$ \\
\hline SLC2-A2 & 0.40 & $150-200$ & $32(12)$ & 3 & $0.57 \pm 0.03$ & $4.17 \pm 0.15$ & $2.29 \pm 0.09$ & $1.72 \pm 0.08$ & $15.53 \pm 0.50$ & $18.1 \pm 2.5$ & $9.1 \pm 0.5$ \\
\hline
\end{tabular}

${ }^{a}$ Values in brackets are numbers of aliquots accepted by SAR.

${ }^{b}$ Number of aliquots rejected from the age calculation.

${ }^{c}$ Water contents of all samples were specified as $5 \pm 3 \%$.

in consideration of their currently measured values, and an uncertainty of $3 \%$ was used to cover variations throughout the burial. The radioactive element concentrations were then converted to a dose rate according to the function of Aitken (1998). The cosmic ray contribution to the dose rate for each sample was estimated as a function of the density of cover deposits, depth, altitude, and geomagnetic latitude proposed according to Prescott and Hutton (1994).

\section{DATING RESULTS}

\section{OSL Characteristics}

Most of the OSL signals decreased to a level undistinguishable from the background within the first second of stimulation, indicating the dominance of the fast component, which is preferable for OSL dating (Figure 4D). The growth curves of different aliquots from the same sample, as exemplified by the sample SLC2A-1, were quite similar in shapes, corroborating the existence of SGC (Figure 4C).

\section{Age of the Siling Co Site}

Table 2 lists the OSL dating results of nine samples from four sections, and artifacts were found and collected from the surface of two sections (17SLC16 and SLC2A). Sample $17 \mathrm{SLC} 16-\mathrm{A}$ showed an age of $10.2 \pm 0.7 \mathrm{ka}$. One sample from section $17 \mathrm{SLC} 17$ was dated at $7.8 \pm 0.5 \mathrm{ka}$. In section 17SLC15, except sample 17SLC15-C at $1.95 \mathrm{~m}$ depth, the ages of other four samples range from $7.4 \pm 0.5$ to $9.6 \pm 0.8 \mathrm{ka}$, which were consistent with each other at $2 \sigma$ range. The duplicate samples from section SLC2A showed a similar age $(8.6 \pm 0.6$ and $9.1 \pm 0.5 \mathrm{ka})$ within $1 \sigma$ uncertainties (Figure 3B), supporting the well-bleaching assumption in OSL dating. The anomalously young age of $17 \mathrm{SLC} 15-\mathrm{C}(6.3 \pm 0.5 \mathrm{ka})$ may arise from the introduction of light-exposed sediments from the above through crevasses and was excluded in the following analysis.

Collectively, these dating results suggest an early Holocene age ( $\sim 10-7 \mathrm{ka} ; \sim 8.54 \pm 0.21 \mathrm{ka}$ in average) for the $4,600 \mathrm{~m}$ paleoshoreline. As stone tools in our field investigation were found on the surface of the 4,600 m paleo-shoreline, the age of the Siling Co site should be no earlier than the early Holocene.

\section{DISCUSSION}

\section{Paleoclimatic Implications of the Age of the 4,600 $\mathrm{m}$ Paleo-Shoreline}

Thanks to their direct geomorphic indication of past water levels, paleo-shorelines have been widely used to reconstruct lake-level fluctuations, which in turn may shed light on climate changes (e.g. Liu et al., 2010; Goldsmith et al., 2017; Yu et al., 2019; Jonell et al., 2020) and lithospheric rheology (e.g. Shi et al., 2015; Henriquet et al., 2019). Previous studies have demonstrated that the amplitude of surface deformation due to changes in lake levels on the TP is no more than $\sim 2-4 \mathrm{~m}$ (Shi et al., 2015; Henriquet et al., 2019), thus corrections for paleo-shoreline elevation were not made in this study.

The OSL dating of different protocols and the exposure dating with cosmogenic nuclides $\left({ }^{36} \mathrm{Cl},{ }^{26} \mathrm{Al}\right.$, and $\left.{ }^{10} \mathrm{Be}\right)$ have been applied to multiple paleo-shorelines of Siling Co (Li et al., 2009; Xue et al., 2010; Kong et al., 2011; Shi et al., 2015, 2017; Hou et al., 2021), but consensus on the ages have yet to be reached. With the fine-grain (4-11 $\mu \mathrm{m})$ quartz and polymineral OSL technique, Li et al. (2009) obtained different ages for two samples, that is, $18.6 \mathrm{ka}$ for sample SW-L1/01 at 4,597 $\mathrm{m}$ asl and $9.6 \mathrm{ka}$ for sample SW-L2/11 at $4,598 \mathrm{~m}$ asl. It is noted that only fractions $<63 \mu \mathrm{m}$ were used in $\mathrm{U}$, $\mathrm{Th}$, and $\mathrm{K}$ analysis, and the resultant bias in dose rate estimation may weaken the reliability of OSL ages. Shi et al. (2015) applied the coarse-grain $(180-212 \mu \mathrm{m})$ quartz OSL dating to paleoshorelines at 4,592 and $4,594 \mathrm{~m}$ asl, and seven of the nine results were approximately between 6 and $4 \mathrm{ka}$. As large overdispersion values were observed in nearly all samples, possibly due to a small aliquot size $(2 \mathrm{~mm})$ and test dose value (5 Gy), which led to a low signal intensity, they used the minimum age model and finite mixture model for age calculation. The reliability of their dating results awaits further examination. A recent OSL-based chronological study of paleoshorelines $<4,565.7 \mathrm{~m}$ asl, though not as high as $4,600 \mathrm{~m}$ asl, revealed a highstand of the lake level at $\sim 10-7 \mathrm{ka}$ (Hou et al., 


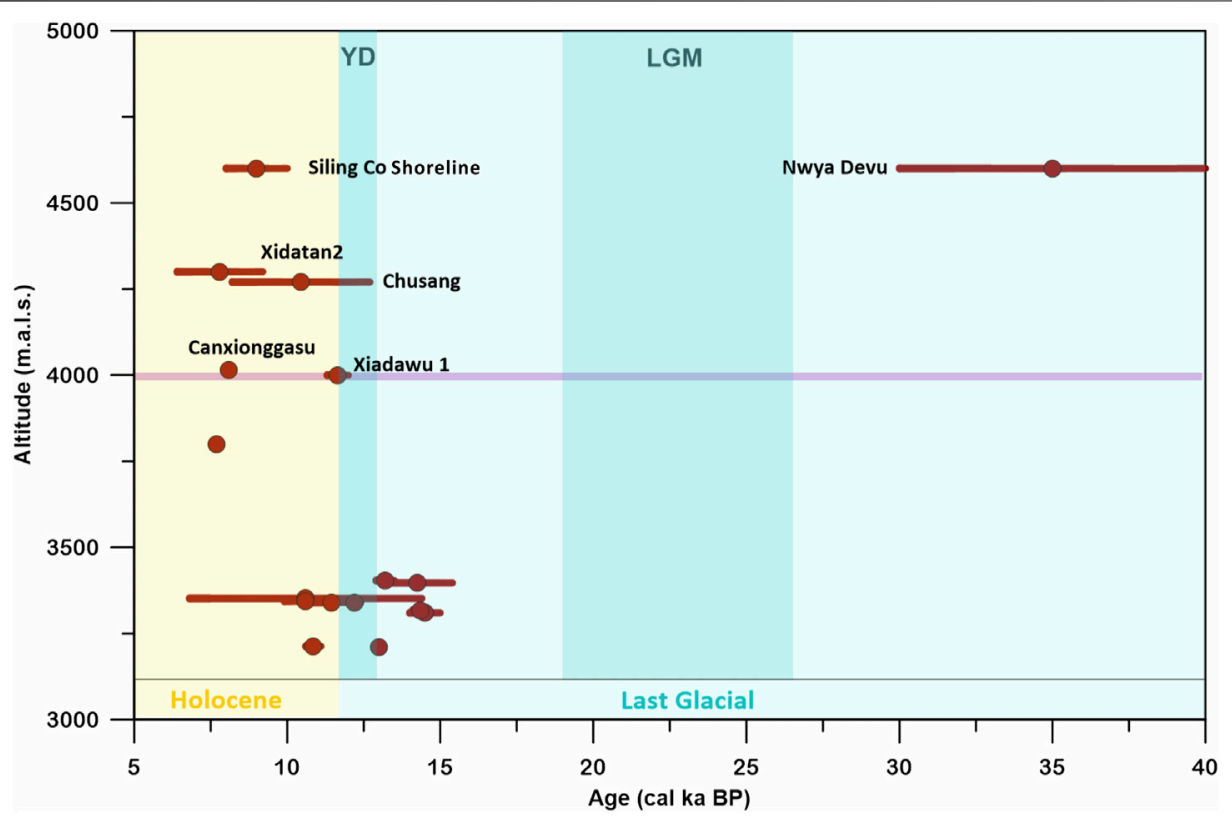

FIGURE 5| The ages and altitudes of paleolithic-microlithic sites on the Tibetan Plateau. The names of sties at elevation >4,000 $m$ (pink line) are indicated. Note that the Siling Co shoreline age here represents the maximum age of the Siling Co site.

2021), supporting the assignment of an early Holocene age to the $\sim 4,600$ m-paleo-shoreline in this study, which was the highest one in our field reconnaissance.

During the early Holocene, a warm and wet climate has been widely reported from the lake sediments (Wei and Gasse, 1999; Wu et al., 2006) and ice-core records (Thompson et al., 1989) on the TP. Previous studies on lake shorelines in the TP also show high lake levels during this period (e.g. Pan et al., 2012; Chen et al., 2013; Hudson et al., 2015). The 10-7 ka shoreline in Siling Co indicates that this lake also achieved a high lake level in the early Holocene, which is consistent with the environment and climate change during this time. Compared with the extremely cold climate during the Last Glacial period, the warm and wet climate in the Holocene provided favorable conditions for ancient human activities, encouraging their expansion and occupation.

\section{Archaeological Implications of the Age of the Siling Co Paleolithic Site}

Climate change is considered an important driving factor in prehistoric human evolution. The basic coupling model of early human migration and climate change can be summarized as follows (Zhang et al., 2016; Madsen et al., 2017): During the warm climate, the living conditions at high latitudes/altitudes would gradually improve, and humans would spread to higher latitudes/altitudes due to internal competition or attraction from the external environment. When the climate becomes cold, humans would retreat from high to low latitudes/altitudes and then reinhabit the high latitudes/ altitudes when the weather gets warmer.
The northeastern margin of the TP is widely considered as the main path for early human migration to the inner plateau. Here, we summarized the available paleolithic-microlithic sites with dating results (Figure 5 and Supplementary Table S1). It can be seen that early humans were mainly active in the middle Yellow River during 35-20 ka (e.g., Shuidonggou) (Nian et al., 2014; Pei et al., 2014). They may temporarily reach the low-altitude areas at the edge of the TP during the warm climate. During LGM, the climate would be hard for early humans to explore further west (Sun et al., 2018). During the last deglacial interval (16-11.5 ka), with the improvement of climatic conditions, early humans reentered the TP through the northwestern margin and reached the Qinghai Lake area (Sun et al., 2018). A series of archaeological sites of 14-11 ka have been found on the northeastern edge of the TP ( 3,200 $\mathrm{m}$ asl) (e.g., Madsen et al., 2006; Brantingham et al., 2007; Sun et al., 2012; Madsen et al., 2017). At the beginning of Holocene, with the strengthening of the Asian monsoon (Dykoski et al., 2005), the climate of the TP turned warmer, the temperature and precipitation had risen to a similar level to that of today (Shen et al., 2006). Humans further expanded to the hinterland of the TP, including the high-altitude areas $(>4,000 \mathrm{~m}$ asl). Several sites such as Xiadawu 1(Hou et al., 2016; Madsen et al., 2017), Xiao Qaidam (Sun et al., 2010), and Xidatan 2 (Brantingham et al., 2013) were discovered in this time. In this study, the age of the Siling Co site is revised from 40 to $30 \mathrm{ka}$ to within the Holocene, making it consistent with this pattern of human settlement on the TP.

Recently, the ND Paleolithic site was reported from a terrace of Co Ngoin Lake at an elevation of $\sim 4,600 \mathrm{~m}$ (Zhang et al., 2018) and is only $\sim 39 \mathrm{~km}$ to the west of the Siling Co site. Considering age revisal at Chusang (Meyer et al., 2017) and Siling Co (this study) 
sites, an OSL-derived age of $\sim 40-30$ ka has made ND the unique evidence of human presence in the interior of the TP where the average elevation is above 4,000 $\mathrm{m}$ (Zhang et al., 2018). If the age is accurate, there are two questions to be considered. On the one hand, it triggered new thinking about the migration of early humans to the high altitudes of the TP. Considering the similarity of the stone tool technology at ND and Shuidonggou ( 43 ka) (Nian et al., 2014; Zhang et al., 2018) along the middle Yellow River in the northeastern TP, it is possible that early humans rapidly migrated along the Yellow River and reached the high-altitude areas of the TP. However, the two sites are geographically apart with a linear distance of $\sim 1,800 \mathrm{~km}$ and an altitude difference of $\sim 3,400 \mathrm{~m}$, and it would be a considerable challenge for early humans to migrate between them. Therefore, there may be other paths from the western or southern TP for early humans to reach the hinterland of the TP (Lv, 2014; Qiu, 2015; Wang et al., 2018). On the other hand, the age of the ND site is interesting in the context of climatic setting. Around the late period of the last ice age at $40-30 \mathrm{ka}$, climate over most of the regions on Earth was much colder and drier than today (Jouzel et al., 2007; Beck et al., 2018). Some studies (e.g. Lai et al., 2014; Yu et al., 2019) also suggested that the TP experienced the same climate as the rest of the world. Therefore, why did humans step into the interior of the TP under such a severe climatic condition? And what happened with these humans during the following LGM period? Were they locally extinct due to the extreme severe climate condition, or did they retreat to the lower area? More systematic survey combined with careful dating is needed to solve these problems.

\section{CONCLUSION}

Through dating nine samples from four sections along the paleoshoreline at $\sim 4,600$ masl, where stone artifacts were found previously and in this study, we postulate that the age of the Siling Co Paleolithic site, which was previously assumed to be $\sim 40-30 \mathrm{ka}$, should be no earlier than the early Holocene $(\sim 10-7 \mathrm{ka} ; \sim 8.54 \pm 0.21 \mathrm{ka}$ in average). The revised age of the

\section{REFERENCES}

Aitken, M. J. (1998). An Introduction to Optical Dating. Oxford, UK: Oxford University Press.

Beck, J. W., Zhou, W., Li, C., Wu, Z., White, L., Xian, F., et al. (2018). A 550,000year Record of East Asian Monsoon Rainfall from10Be in Loess. Science 360, 877-881. doi:10.1126/science.aam5825

Brantingham, P. J., Gao, X., Olsen, J. W., Ma, H., Rhode, D., Zhang, H., et al. (2007). A Short Chronology for the Peopling of the Tibetan Plateau. Dev. Quat. Sci. 9, 129-150. doi:10.1016/s1571-0866(07)09010-0

Brantingham, P. J., Rhode, D., and Madsen, D. B. (2010). Archaeology Augments Tibet's Genetic History. Science 329, 1467. doi:10.1126/ science.329.5998.1467-a

Brantingham, P. J., Xing, G., Madsen, D. B., Rhode, D., Perreault, C., Van Der Woerd, J., et al. (2013). Late Occupation of the High-Elevation Northern Tibetan Plateau Based on Cosmogenic, Luminescence, and Radiocarbon Ages. Geoarchaeology 28, 413-431. doi:10.1002/gea.21448

Chen, F. H., Dong, G. H., Zhang, D. J., Liu, X. Y., Jia, X., An, C. B., et al. (2015). Agriculture Facilitated Permanent Human Occupation of the
Siling Co site is consistent with a current model that assumes that humans did not widely occupy the interior of the TP until the Holocene. We call for further examination on the age of other high-elevation Paleolithic sites dated to the LGM or earlier.

\section{DATA AVAILABILITY STATEMENT}

The original contributions presented in the study are included in the article/Supplementary Material; further inquiries can be directed to the corresponding authors.

\section{AUTHOR CONTRIBUTIONS}

ZL organized the project. $\mathrm{ZL}, \mathrm{LY}$, and $\mathrm{CH}$ collected the OSL samples. WZ and $\mathrm{CH}$ conducted the experiments in the laboratory. LL and ZL performed data analysis. LL, ZL, and YX wrote the manuscript. ZL, YX, and HT reviewed the manuscript and contributed to data interpretation. HT took photos for the artifacts. ZL proofread the manuscript. All authors contributed to discussions.

\section{FUNDING}

This study was supported by CNSF (41290252) and STU Scientific Research Foundation for Talents (NTF19003). The authors would like to thank Zhixiang Wang, Weitao Yuan, and Yanqing Deng for help in the field and Peisong Zheng and Qinjing Shen for constructive discussions.

\section{SUPPLEMENTARY MATERIAL}

The Supplementary Material for this article can be found online at: https://www.frontiersin.org/articles/10.3389/feart.2021.699693/ full\#supplementary-material

Tibetan Plateau after 3600 B.P. Science 347, 248-250. doi:10.1126/ science. 1259172

Chen, F., Welker, F., Shen, C.-C., Bailey, S. E., Bergmann, I., Davis, S., et al. (2019). A Late Middle Pleistocene Denisovan Mandible from the Tibetan Plateau. Nature 569, 409-412. doi:10.1038/s41586-019-1139-x

Chen, Y., Zong, Y., Li, B., Li, S., and Aitchison, J. C. (2013). Shrinking Lakes in Tibet Linked to the Weakening Asian Monsoon in the Past 8.2 Ka. Quat. Res. 80, 189-198. doi:10.1016/j.yqres.2013.06.008

Dykoski, C., Edwards, R., Cheng, H., Yuan, D., Cai, Y., Zhang, M., et al. (2005). A High-Resolution, Absolute-Dated Holocene and Deglacial Asian Monsoon Record from Dongge Cave, China. Earth Planet. Sci. Lett. 233, 71-86. doi:10.1016/j.epsl.2005.01.036

Goldsmith, Y., Broecker, W. S., Xu, H., Polissar, P. J., deMenocal, P. B., Porat, N., et al. (2017). Northward Extent of East Asian Monsoon Covaries with Intensity on Orbital and Millennial Timescales. Proc. Natl. Acad. Sci. USA 114, 1817-1821. doi:10.1073/pnas.1616708114

Henriquet, M., Avouac, J.-P., and Bills, B. G. (2019). Crustal Rheology of Southern Tibet Constrained from Lake-induced Viscoelastic Deformation. Earth Planet. Sci. Lett. 506, 308-322. doi:10.1016/ j.epsl.2018.11.014 
Hou, G., Cao, G., Chongyi, E., Ren, X., Wuennemann, B., and Li, F. (2016). New Evidence of Human Activities at an Altitude of 4000 Meters Area of QinghaiTibet Plateau. Acta Geogr. Sinica 71, 1231-1240. doi:10.11821/dlxb201607011

Hou, Y., Long, H., Shen, J., and Gao, L. (2021). Holocene Lake-level Fluctuations of Selin Co on the central Tibetan Plateau: Regulated by Monsoonal Precipitation or Meltwater? Quat. Sci. Rev. 261, 106919. doi:10.1016/j.quascirev.2021.106919

Huang, W. W., Chen, K. Z., and Yuan, B. Y. (1987). "Paleolithics of Xiao Qaidam Lake in Qinghai Province in China," in Proceedings of the Sino-Australian Quaternary Meeting, (Beijing: Sciences Press), 168-172.

Hudson, A. M., Quade, J., Huth, T. E., Lei, G., Cheng, H., Edwards, L. R., et al. (2015). Lake Level Reconstruction for 12.8-2.3 Ka of the Ngangla Ring Tso Closed-Basin Lake System, Southwest Tibetan Plateau. Quat. Res. 83, 66-79. doi:10.1016/j.yqres.2014.07.012

Jonell, T. N., Aitchison, J. C., Li, G., Shulmeister, J., Zhou, R., and Zhang, H. (2020). Revisiting Growth and Decline of Late Quaternary Mega-Lakes Across the South-central Tibetan Plateau. Quat. Sci. Rev. 248, 106475. doi:10.1016/ j.quascirev.2020.106475

Jouzel, J., Masson-Delmotte, V., Cattani, O., Dreyfus, G., Falourd, S., Hoffmann, G., et al. (2007). Orbital and Millennial Antarctic Climate Variability Over the Past 800,000 Years. Science 317, 793-796. doi:10.1126/science.1141038

Kong, P., Na, C., Brown, R., Fabel, D., Freeman, S., Xiao, W., et al. (2011). Cosmogenic 10Be and 26Al Dating of Paleolake Shorelines in Tibet. J. Asian Earth Sci. 41, 263-273. doi:10.1016/j.jseaes.2011.02.016

Lai, Z.-P., Brückner, H., Zöller, L., and Fülling, A. (2007). Existence of a Common Growth Curve for Silt-sized Quartz OSL of Loess from Different Continents. Radiat. Measurements 42, 1432-1440. doi:10.1016/ j.radmeas.2007.08.006

Lai, Z., Mischke, S., and Madsen, D. (2014). Paleoenvironmental Implications of New OSL Dates on the Formation of the "Shell Bar" in the Qaidam Basin, Northeastern Qinghai-Tibetan Plateau. J. Paleolimnol. 51, 197-210. doi:10.1007/s10933-013-9710-1

Lai, Z. (2006). Testing the Use of an OSL Standardised Growth Curve (SGC) for Determination on Quartz from the Chinese Loess Plateau. Radiat. Measurements 41, 9-16. doi:10.1016/j.radmeas.2005.06.031

Li, D., Li, Y., Ma, B., Dong, G., Wang, L., and Zhao, J. (2009). Lake-level Fluctuations since the Last Glaciation in Selin Co (lake), Central Tibet, Investigated Using Optically Stimulated Luminescence Dating of beach Ridges. Environ. Res. Lett. 4, 045204. doi:10.1088/1748-9326/4/4/045204

Liu, X., Lai, Z., Fan, Q., Long, H., and Sun, Y. (2010). Timing for High lake Levels of Qinghai Lake in the Qinghai-Tibetan Plateau Since the Last Interglaciation Based on Quartz OSL Dating. Quat. Geochronol. 5, 218-222. doi:10.1016/ j.quageo.2009.03.010

Lv, H. (2014). Trans-Himalaya Cultural Interactions in Western Tibetan Neolithic Age. Archaeology 12, 77-89.

Madsen, D. B., Haizhou, M., Brantingham, P. J., Xing, G., Rhode, D., Haiying, Z., et al. (2006). The Late Upper Paleolithic Occupation of the Northern Tibetan Plateau Margin. J. Archaeological Sci. 33, 1433-1444. doi:10.1016/ j.jas.2006.01.017

Madsen, D. B., Perreault, C., Rhode, D., Sun, Y., Yi, M., Brunson, K., et al. (2017). Early Foraging Settlement of the Tibetan Plateau highlands. Archaeological Res. Asia 11, 15-26. doi:10.1016/j.ara.2017.04.003

Meng, K., Shi, X., Wang, E., and Liu, F. (2012). High-altitude Salt lake Elevation Changes and Glacial Ablation in Central Tibet, 2000-2010. Chin. Sci. Bull. 57, 525-534. doi:10.1007/s11434-011-4849-5

Meyer, M. C., Aldenderfer, M. S., Wang, Z., Hoffmann, D. L., Dahl, J. A., Degering, D., et al. (2017). Permanent Human Occupation of the Central Tibetan Plateau in the Early Holocene. Science 355, 64-67. doi:10.1126/ science.aag0357

Murray, A. S., and Wintle, A. G. (2000). Luminescence Dating of Quartz Using An Improved Single-Aliquot Regenerative-Dose Protocol. Radiat. Measurements 32, 57-73. doi:10.1016/s1350-4487(99)00253-x

Murray, A. S., and Wintle, A. G. (2003). The Single Aliquot Regenerative Dose Protocol: Potential for Improvements in Reliability. Radiat. Measurements 37, 377-381. doi:10.1016/s1350-4487(03)00053-2

Nian, X., Gao, X., and Zhou, L. (2014). Chronological Studies of Shuidonggou (SDG) Locality 1 and Their Significance for Archaeology. Quat. Int. 347, 5-11. doi:10.1016/j.quaint.2014.03.050
Pan, B., Yi, C., Jiang, T., Dong, G., Hu, G., and Jin, Y. (2012). Holocene Lake-level Changes of Linggo Co in Central Tibet. Quat. Geochronol. 10, 117-122. doi:10.1016/j.quageo.2012.03.009

Pei, S., Niu, D., Guan, Y., Nian, X., Kuman, K., Bae, C. J., et al. (2014). The Earliest Late Paleolithic in North China: Site Formation Processes at Shuidonggou Locality 7. Quat. Int. 347, 122-132. doi:10.1016/j.quaint.2014.03.052

Prescott, J. R., and Hutton, J. T. (1994). Cosmic Ray Contributions to Dose Rates for Luminescence and ESR Dating: Large Depths and Long-Term Time Variations. Radiat. Measurements 23, 497-500. doi:10.1016/1350-4487(94) 90086-8

Qiu, J. (2015). Who Are the Tibetans? Science 347, 708-711. doi:10.1126/ science. 347.6223 .708

Roberts, H. M., and Duller, G. A. T. (2004). Standardised Growth Curves for Optical Dating of Sediment Using Multiple-Grain Aliquots. Radiat. Measurements 38, 241-252. doi:10.1016/j.radmeas.2003.10.001

Shen, C., Liu, K.-b., Tang, L., and Overpeck, J. T. (2006). Quantitative Relationships Between Modern Pollen Rain and Climate in the Tibetan Plateau. Rev. Palaeobotany Palynology 140, 61-77. doi:10.1016/j.revpalbo.2006.03.001

Shi, X., Furlong, K. P., Kirby, E., Meng, K., Marrero, S., Gosse, J., et al. (2017). Evaluating the Size and Extent of Paleolakes in Central Tibet During the Late Pleistocene. Geophys. Res. Lett. 44, 5476-5485. doi:10.1002/2017gl072686

Shi, X., Kirby, E., Furlong, K. P., Meng, K., Robinson, R., and Wang, E. (2015). Crustal Strength in Central Tibet Determined from Holocene Shoreline Deflection Around Siling Co. Earth Planet. Sci. Lett. 423, 145-154. doi:10.1016/j.epsl.2015.05.002

Simonson, T. S., Yang, Y., Huff, C. D., Yun, H., Qin, G., Witherspoon, D. J., et al. (2010). Genetic Evidence for High-Altitude Adaptation in Tibet. Science 329, 72-75. doi:10.1126/science.1189406

Sun, Y., Chongyi, E., Lai, Z., and Hou, G. (2018). Luminescence Dating of Prehistoric Hearths in Northeast Qinghai Lake and its Paleoclimatic Implication. Archaeol Anthropol. Sci. 10, 1525-1534. doi:10.1007/s12520017-0472-y

Sun, Y., Lai, Z., Long, H., Liu, X., and Fan, Q. (2010). Quartz OSL Dating of Archaeological Sites in Xiao Qaidam Lake of the NE Qinghai-Tibetan Plateau and its Implications for Palaeoenvironmental Changes. Quat. Geochronol. 5, 360-364. doi:10.1016/j.quageo.2009.02.013

Sun, Y., Lai, Z., Madsen, D., and Hou, G. (2012). Luminescence Dating of a Hearth from the Archaeological Site of Jiangxigou in the Qinghai Lake Area of the Northeastern Qinghai-Tibetan Plateau. Quat. Geochronol. 12, 107-110. doi:10.1016/j.quageo.2012.01.010

Tang, H., Zhou, C., Li, Y., and Liang, Z. (2013). A New Discovery of Microlithic Information at the Entrance to the Northern Qingzang Plateau of the Kunlun Mountains of Qinghai. Chin. Sci. Bull. 58, 247-253. doi:10.1360/972012-550

Thompson, L. G., Mosley-Thompson, E., Davis, M. E., Bolzan, J. F., Dai, J., Klein, L., et al. (1989). Holocene--Late Pleistocene Climatic Ice Core Records from Qinghai-Tibetan Plateau. Science 246, 474-477. doi:10.1126/ science.246.4929.474

Wang, J., Xia, H., Yao, J., Shen, X., Cheng, T., Wang, Q., et al. (2020). Subsistence Strategies of Prehistoric Hunter-gatherers on the Tibetan Plateau During the Last Deglaciation. Sci. China Earth Sci. 63, 395-404. doi:10.1007/s11430-0199519-8

Wang, S., Zhang, X., and Chen, Z. (2018). Acheulian-like Tools Found at Nyade Site in North Tibet-With Discussions on Human Occupation of Tibetan Plateau in Late Pleistocene. Acta Anthropol. Sinica 37, 253-269. doi:10.16359/ j.cnki.cn11-1963/q.2018.0006

Wei, K., and Gasse, F. (1999). Oxygen Isotopes in Lacustrine Carbonates of West China Revisited: Implications for Post Glacial Changes in Summer Monsoon Circulation. Quat. Sci. Rev. 18, 1315-1334. doi:10.1016/s0277-3791(98)00115-2

Wu, Y., Lücke, A., Jin, Z., Wang, S., Schleser, G. H., Battarbee, R. W., et al. (2006). Holocene Climate Development on the Central Tibetan Plateau: A Sedimentary Record from Cuoe Lake. Palaeogeogr. Palaeoclimatol. Palaeoecol. 234, 328-340. doi:10.1016/j.palaeo.2005.09.017

Xue, L., Zhang, Z., Liu, W., Lv, T., and Sun, J. (2010). The Shrinking Process of Siling Co in the Past 12 Ka: Based on OSL Dating of Past Shorelines. Chin. J. Geol. 45, 428-439.

Yi, M., Gao, X., Zhang, X., Sun, Y., Brantingham, P. J., Madsen, D. B., et al. (2011). A Preliminary Report on Investigations in 2009 of Some Prehistoric Sites in the Tibetan Plateau Marginal Region. Acta Anthropol. Sinica 30, 124-136. 
Yi, X., Liang, Y., Huerta-Sanchez, E., Jin, X., Cuo, Z. X. P., Pool, J. E., et al. (2010). Sequencing of 50 Human Exomes Reveals Adaptation to High Altitude. Science 329, 75-78. doi:10.1126/science.1190371

Yu, S.-Y., Colman, S. M., and Lai, Z.-P. (2019). Late-Quaternary History of 'great lakes' on the Tibetan Plateau and Palaeoclimatic Implications - A Review. Boreas 48, 1-19. doi:10.1111/bor.12349

Yuan, B., Huang, W., and Zhang, D. (2007). New Evidence for Human Occupation of the Northern Tibetan Plateau, China During the Late Pleistocene. Chin. Sci Bull 52, 2675-2679. doi:10.1007/s11434-007-0357-z

Zhang, D. D., and Li, S. H. (2002). Optical Dating of Tibetan Human Handand Footprints: An Implication for the Palaeoenvironment of the Last Glaciation of the Tibetan Plateau. Geophys. Res. Lett. 29, 1072. doi:10.1029/ 2001gl013749

Zhang, D., Dong, G., Wang, H., Ren, X., Ha, P. u., Qiang, M., et al. (2016). History and Possible Mechanisms of Prehistoric Human Migration to the Tibetan Plateau. Sci. China Earth Sci. 59, 1765-1778. doi:10.1007/s11430-015-5482-x

Zhang, D., Xia, H., Chen, F., Li, B., Slon, V., Cheng, T., et al. (2020). Denisovan DNA in Late Pleistocene Sediments from Baishiya Karst Cave on the Tibetan Plateau. Science 370, 584-587. doi:10.1126/science.abb6320

Zhang, X. L., Ha, B. B., Wang, S. J., Chen, Z. J., Ge, J. Y., Long, H., et al. (2018). The Earliest Human Occupation of the High-Altitude Tibetan Plateau 40 Thousand to 30 Thousand Years Ago. Science 362, 1049-1051. doi:10.1126/science.aat8824
Zhao, M., Kong, Q.-P., Wang, H.-W., Peng, M.-S., Xie, X.-D., Wang, W.-Z., et al. (2009). Mitochondrial Genome Evidence Reveals Successful Late Paleolithic Settlement on the Tibetan Plateau. Pnas 106, 21230-21235. doi:10.1073/ pnas.0907844106

Conflict of Interest: The authors declare that the research was conducted in the absence of any commercial or financial relationships that could be construed as a potential conflict of interest.

Publisher's Note: All claims expressed in this article are solely those of the authors and do not necessarily represent those of their affiliated organizations, or those of the publisher, the editors and the reviewers. Any product that may be evaluated in this article, or claim that may be made by its manufacturer, is not guaranteed or endorsed by the publisher.

Copyright (c) 2021 Luo, Lai, Zheng, Xu, Yu, Huang and Tu. This is an open-access article distributed under the terms of the Creative Commons Attribution License (CC $B Y)$. The use, distribution or reproduction in other forums is permitted, provided the original author(s) and the copyright owner(s) are credited and that the original publication in this journal is cited, in accordance with accepted academic practice. No use, distribution or reproduction is permitted which does not comply with these terms. 